\title{
Lokasyon Katsayısı Yaklaşımı İle Türkiye Çimento Sanayiinde Bölgesel Yoğunlaşma*
}

\section{Regional Concentration in the Turkish Cement Industry with the Location Coefficient Approach}

\author{
Adnan ALKAN ${ }^{a}$ \\ Zehra OBUT BİLìm \\ ${ }^{a}$ Doç. Dr. Siirt Üniversitesi, Fen- \\ Edebiyat Fakültesi, Coğrafya Bölümü, \\ Siirt/Türkiye,ad_alkan@hotmail.com \\ ORCID: orcid.org/0000-0002-5377- \\ 4726 \\ ${ }^{\mathrm{b}}$ Arş. Gör. Siirt Üniversitesi, Fen- \\ Edebiyat Fakültesi, Coğrafya Bölümü, \\ Siirt/Türkiye, zhrobut@gmail.com \\ ORCID: orcid.org/0000-0001-9791- \\ 2054
}

\begin{abstract}
ÖZ
Kümelenme, bölgesel kalkınmada önemli bir araçtır. Türkiye'de hemen hemen her bölgede yer alan çimento sanayinin, hangi bölgelerde yoğunlaşma potansiyelinin olduğu ya da hangi bölgelerde yoğunlaştığı üzerinde durulması gereken bir konudur. Özellikle geri kalmış bölgelerde yer alması ekonomik kalkınma açısından önemli bir role sahiptir. Bu çalışmada, İBBS Düzey2 bölgelerinde, NACE 2 koduna göre 23.51 kodlu Türkiye çimento sanayiinin yerel birim sayısı ve istihdama göre yoğunlaşma oranları, Yoğunlaşma Katsayısı (Location Quotient-LQ) yöntemi ile analiz edilmiştir. Buna göre 2014 yılında yerel birim sayısına (sanayi tesisi) göre yoğunlaşma katsayısı en yüksek bölgeler, TR72, TRC2, TR62 ve TR63 bölgeleridir. 2019 y1lında ise; TRC2, TR90, TR72 ve TR63 bölgeleridir. İstihdam katsayısına göre 2014 yılında istihdamda en fazla yoğunluk gösteren bölgeler, TR81, TR52, TRA1 ve TRA2 bölgeleridir. 2019 y1lında ise; TRC3, TR62, TR90, TR52 ve TR63 bölgeleridir. Sonuç olarak; Türkiye'de yerel birim sayısı ve istihdam göstergelerine göre Çimento sanayiinde TR82 (Kastamonu, Çankırı, Sinop) ve TR22 (Balıkesir, Çanakkale) bölgeleri dışında kalan neredeyse tüm bölgelerde yoğunlaşma görülmektedir.
\end{abstract}

Anahtar Kelimeler: Çimento, Lokasyon Katsayısı, Bölgesel, Kümelenme, Türkiye.

\begin{abstract}
Clustering is an important tool in regional development. It is a matter that needs to be emphasized in which regions the cement industry, which is located in almost every region in Turkey, has the potential to concentrate or in which regions it is concentrated. Especially in underdeveloped regions, it has an important role in terms of economic development. In this study, the concentration ratios of the Turkish cement industry, coded 23.51 according to NACE 2 code, in NUTS Level 2 regions, and the concentration ratios according to employment were analysed by the Concentration Quotient-LQ method. Accordingly, in 2014, the regions with the highest concentration coefficient according to the number of local units (industrial facilities) are TR72, TRC2, TR62 and TR63 regions. In 2019; TRC2, TR90, TR72 and TR63 regions. According to the employment coefficient, the regions with the highest employment density in 2014 are TR81, TR52, TRA1 and TRA2. In 2019; TRC3, TR62, TR90, TR52 and TR63 are region. As a result; according to the local unit number and employment indicators in Turkey, concentration is observed in almost all regions except TR82 (Sinop, Kastamonu, Çankırı) and TR22 (Balıkesir, Çanakkale) regions in the cement industry.
\end{abstract}

Keywords: Cement, Location Coefficient, Regional, Clustering, Turkey.

\footnotetext{
* Bu makalede bilimsel araştırma ve yayın etiği ilkelerine uyulmuştur. / In this article, the principles of scientific research and publication ethics were followed.
} 


\section{GíRiş}

Çimento, doğal kil ve kalker karışımının yüksek sıcaklıkta pişirildikten sonra öğütülmesi ile elde edilen hidrolik bir bağlayıcı ürün olarak tanımlanmaktadır. Hidrolik bağlayıcı ürünler, su ile etkileşim sonucu sert bir kütle meydana geldikten sonra su içerisinde dağılmayan, sertliğini koruyan bağlayıcı malzemelerdir (Çakmak, 1998: 26, Sarı vd., 2020: 848). Çimento, kalsiyum, silisyum, alüminyum ve demir oksitleri içeren hammaddelerin teknolojik yöntemlerle sinterleşme derecesine kadar pişirilmesi ile elde edilen yarı mamul madde olan klinkerin tek veya daha fazla tür katkı maddesi ile öğütülmesi yoluyla üretilmektedir (Kapkaç, 2013: 223, Çakmak, 1998: 26). Üç aşamadan meydana gelen çimento üretimi işlemi şu şekildedir: Hammaddenin hazırlanması, hazırlanan hammaddenin enerji kaynakları ile pişirilmesi, pişirilen hammaddenin çeşitli katkı maddeleri eklenerek öğütülmesi olarak sıralanabilir. Çimentonun üretilmesinde kullanılan iki ana malzemeden biri doğadan doğrudan elde edilen alçıtaşı diğeri ise yarı mamul olan klinkerdir. Bunların yanında silis dumanı, puzolan, uçucu kül, pişmiş şist, yüksek firın cürufu, kırmızı çamur ve bunlara benzer malzemeler de üretilecek çimento türüne göre katkı maddesi olarak kullanılmaktadır. Klinkere öğütme esnasında alçı taşı eklenirse üretilen çimentoya Portland Çimentosu, diğer maddeler da katılırsa Katkılı Çimento denir (Tunçez, 2021: 42-43, Miller \& Osborne, 2014: 223).

Öte yandan dünyada ilk çimento üretimi İngiltere'nin Leeds kentinde 1824 yılında Joseph Aspdin tarafından kil ve ince taneli kalker karışımının pişirilmesinden sonra ögütülerek gerçekleştirilmiştir. Üretilen çimentonun rengi ve özellikleri Leeds yakınlarındaki Portland adlı adadan getirilen doğal yapı taşına benzediği için ismine Portland Çimentosu denilmiştir. Bu çimento yeterli sıcaklıkta pişirilmediği için bir takım olumsuz tarafları görülmüştür. Bu nedenle Isaac Johnson isimli İngiliz 1845 yılında, Portland Çimentosunun niteliklerini iyi pişirmeden sonra geliştirerek günümüzde dünyanın her tarafında kullanılır hale getirmiştir. 1845 yılından bu yana üretilmekte olan çimento, günümüzde en önemli yapı malzemesi olma özelliğini sürdürmektedir. Bu süreç içinde çimento üretim teknolojisinde büyük aşama sağlanmıştır. Öncelikle yaş öğütme sisteminden kuru öğütme sisteme geçilerek enerjide büyük tasarruf elde edilmiştir (Kapkaç, 2013: 223, Sarı vd., 2020: 848).

İnşaat sektöründe yaygın olarak kullanılan çimento, modern altyapı ve küresel konut gereksinimini karşılamak için üretilmekte olup önemli bir malzeme olarak gelişmişliğin bir kriteri olarak kabul edilmektedir (Supino vd., 2016: 430). Çimento üretiminde hammadde, enerji, yakıt ve yardımcı maddeler, önemli maliyet bileşenleridir. Özellikle, Tablo 1'de de görüldüğü gibi enerji ve yakıt maliyeti toplam maliyet içerisinde en büyük maliyet kalemlerini oluşturmaktadır. Ulaştırma da üretimden ihracata kadar önemli maliyet kalemleri arasında yer almaktadır (Rekabet Kurumu, 2016: 9). Üretim maliyetlerinde yakıt ve enerji giderleri \%60 gibi önemli bir paya sahiptir. Bu özelliği ile çimento sektörü dünyada enerji tüketimi en yüksek sektörler arasında yer almaktadır. Bu nedenle çimento sanayiinde enerjinin etkin ve verimli kullanımı, enerji tasarrufu ve çimentonun çevresel etkilerinin azaltılması gibi konular son yıllarda sektörün en fazla odaklandığı hususlardır (Syed vd., 2020: 1). Bu bağlamda enerji yoğun bir sektör olan çimento sektöründe sürdürülebilir çimento üretimi için alternatif hammadde kullanımı, yenilenebilir enerji kaynaklarına dayalı yakıt kullanımı, çimento içinde klinker kullanım oranının düşürülmesi ve enerji verimliliğinin sağlanması gibi uygulamaların yaygınlaşması gerekmektedir (Ekincioğlu vd., 2013: 137-138; Moretti \& Caro, 2017: 199).

Günümüzde küresel çapta uluslararası ekonomik rekabet giderek artmasından dolayı bazı sektörlerin rolü giderek artmaktadır. Bu sektörler içinde yer alan çimento sektörü bir ülke için ekonomik büyümenin öncü göstergeleri arasında yer almaktadır (Tüzemen \& Yıldız, 2018:162). Küresel boyutta hızla büyüyen ekonomiler için çimento, petrol ya da çelik gibi can alıcı ve temel küresel ticari ürünler içerisinde yer almaktadır. Tüm dünyada artan altyapı ve inşaat yatırımları sayesinde çimento endüstrisi vazgeçilmez yerini korumakta olup küresel çimento pazarı muazzam bir büyüklüğe ulaşmıştır. Her ne kadar ulaşım maliyetlerinin yüksekliğinden dolayı en fazla karayolu ile 300-400 km'lik bir mesafeye kadar ulaştırılması rantabl olan ve daha çok iç pazarda tüketilen çimento buna rağmen küresel pazarda önemli bir konuma sahiptir (Çevik, 2016: 19). Dünya çimento üreticileri yılda yaklaşık 250 milyar Amerika Birleşik Devletleri Doları gelir elde etmektedir (Taner, 2021)

Dünya çimento üretimi zaman zaman ekonomik krizler ve siyasal-toplumsal gelişmeler neticesinde dalgalanmalar göstermesine rağmen sürekli bir artış eğilimindedir. Nitekim 1995 yılında dünya çimento üretimi 1 milyar 390 milyon ton iken, 2010 yılında 3 milyar 310 milyon tona, 2020 yılında ise 4 milyar 100 milyon tona yükselmiştir. Dünya çimento üretiminde altyapı harcamalarının ekonomik büyümede büyük önem arz ettiği Çin, tartışmasız ilk sırada yer alır. Çin, 2020 yılında 2 milyar 200 milyon ton ile dünya çimento üretiminin \%50'sini tek başına karşılamaktadır (www.statista.com). Çin, sadece 2012-2014 döneminde ABD’nin 20. yüzyıldaki toplam çimento üretiminin 1,6 katını gerçekleştirmiştir (Çevik, 2016: 6). Çin'den sonra nüfusun fazla olduğu bir diğer ülke olan Hindistan, yıllık 340 milyon tonluk üretimi ile dünyanın ikinci büyük üreticisi konumundadır (Tablo 1). Son yıllarda üretim kapasitesini oldukça artıran Vietnam 96 milyon tonluk üretimi ile dünyanın üçüncü büyük üreticisi konumundadır. ABD, Endonezya, Türkiye, İran, Brezilya, Rusya ve Japonya, dünya çimento üretiminde ilk 10 ülke içerisinde yer almaktadır (www.statista.com).

Tablo 1: Yıllara göre Dünya Çimento Üretimi (2010-2020)

\begin{tabular}{lcccc}
\hline Ülke & $\mathbf{2 0 2 0}$ (Milyon ton) & 2019 (Milyon ton) & 2015 (Milyon ton) & 2010 (Mil. ton) \\
\hline \hline Çin & 2200 & 2300 & 2350 & 1880 \\
Hindistan & 340 & 340 & 270 & 210 \\
Vietnam & 96 & 97 & 61 & 50
\end{tabular}




\begin{tabular}{lllcc} 
ABD & 90 & 89 & 83,4 & 67,2 \\
Endonezya & 73 & 70 & 65 & 22 \\
Türkiye & 66 & 57 & 77 & 62,7 \\
İran & 60 & 60 & 65 & 50 \\
Brezilya & 57 & 54 & 72 & 59,1 \\
Rusya & 56 & 56 & 69 & 50,4 \\
Japonya & 53 & 53 & 55 & 51,5 \\
\hline \hline
\end{tabular}

Kaynak: https://www.statista.com/statistics/267364/world-cement-production-by-country/ (01/05/2021)

Dünya çimento ihracatı verilerine bakıldığında, 2020 yılında, ilk sırada 1 milyar 600 milyon dolar ile Vietnam, ikinci sırada yaklaşık 1 milyar 200 dolar ile Türkiye ve üçüncü sırada yaklaşık 600 milyon dolar ile Tayland yer almıştır. Vietnam ve Tayland dünya tüketiminin yaklaşık üçte ikisinin gerçekleştiği Asya bölgesi ağırlıklı üretim ve ihracat yapmaktadırlar. Dünyanın en büyük çimento ithalatçı ülkeleri ise sırasıyla Çin, ABD ve Filipinler'dir. Çin 2020 yılında 1.5 milyar dolar, ABD de 1.4 milyar dolar ithalat yapmıştır (T.C. Sanayi ve Teknoloji Bakanlığı, 2020; International Trade Centre, 2021).

Öte yandan Türkiye çimento sektörü, üretimine ilk olarak 1911 yılında Darıca' da kurulan 20.000 ton/yıl kapasiteli bir fırın ile üretime başlamıştır. Daha sonra bu fabrikanın üretim kapasitesi 1923 yılında 40.000 ton/yıl'a yükseltilmiştir. Türkiye'de çimento sektörü 1950'li yıllarda Zeytinburnu (İstanbul), Kartal (İstanbul), Ankara ve Sivas'ta yeni kurulan dört fabrikayla büyümüş ve bu yıllarda üretim kapasitesini 370.000 ton/yıl'a yükseltmiştir (Özeken, 1939: 479; Arı̈z \& Yıldırım, 2012: 176; T.C. Sanayi ve Teknoloji Bakanlığı, 2020: 4). Türkiye Çimento Sanayisi T.A.Ş.'nin (ÇİSAN) 1953 yılında kurulmasıyla Türkiye'de üretimde artış gerçekleştirmesine rağmen, 1970'lere kadar talebin yeterli düzeyde karşılanamaması sebebiyle çimentonun ithalat aracılığıyla karşılanmasına devam edilmiştir. 1970'lerden itibaren Türkiye'de çimentoya olan talebin hızla artmasıyla birlikte dışa bağımlılığı azaltmak ve milli üretimi artırmak için önemli adımlar atılmış ve çimento endüstrisinde sermaye ve giriş sayısı büyük bir hızla artmıştır. Nitekim 1970 yılında 6,4 milyon üretim miktarı, 2010 yılında yaklaşık 10 kat artarak 62 milyon tona yükselmiştir (Arıöz \& Yıldırım, 2012: 176). Türkiye, 2020 yılında ise COVID19 pandemisine rağmen 66 milyon tonluk üretimiyle dünyanın altıncı büyük üreticisi konumundadır (International Trade Centre, 2021).

Türkiye çimento endüstrisi 2020 yılı sektörde 55 entegre tesis ve 21 öğütme tesisine sahiptir. Sektör üretim alanında yaklaşık 19.000 kişiyi istihdam etmektedir (T.C. Sanayi ve Teknoloji Bakanlı̆̆, 2020 ). Günümüzde çimento sanayii, hammadde bakımından tamamen kendi kaynaklarını kullanmakta ve teknolojik olarak en gelişmiş teknolojilerin kullanıldığı bir sektör olarak dikkat çekmektedir. Çimento sektörü, üretimiyle ülke ihtiyacını karşılamasının yanında ithalattaki payı az olmasına rağmen 1 milyar ABD dolarını aşan miktarıyla dünyanın ikinci büyük ihracatçısı konumunda olup, dünyanın 155 ülkesine satış yapılmaktadır (International Trade Centre, 2021). Bu çalışmada Türkiye için oldukça önemli bir sektör olan çimento sektörünün lokasyon katsayısı yöntemi ile bölgesel yoğunlaşması analiz edilmiştir. Türkiye'nin her bölgesine dağılmış olan çimento fabrikaları, pazar, hammadde, yatırım maliyetleri gibi parametrelerin etkisiyle bazı bölgelerde kümelenme göstermiştir.

\section{VERI VE YÖNTEM}

Çalışma alanını İBBS-NUTS; İstatistiki Bölge Birimleri Sınıflandırmasına göre 26 Düzey-2 bölgesi oluşturmaktadır. Çalışmada kullanılan veriler, NACE kodu; Avrupa Topluluğu'nda ekonomik faaliyetlerin istatistiki anlamına gelir. Çalışmada NACE Kod sistemine göre; NACE Rev2 23.51 kodlu çimento sanayii için çalışan sayısı ve yerel birim sayısı olmak üzere iki farklı parametre kullanılmıştır.

Bilimsel çalışmalarda, gözleme ve deneye dayalı, bilinmeyenin ölçümü için bazı modern istatiksel yöntemler kullanılmaktadır (Çubukçu, 2015:1). Ülke düzeyinde sanayi kümelenmesinin coğrafi sınırlarının değişimi ancak nicel analiz yöntemleriyle ortaya konulabilmektedir (Kaygalak, 2013: 69). Çalışmanın nicel analizinde kullanılan veriler; 2014 ve 2019 yıllarına ait olup, bu veriler; Türkiye Odalar ve Borsalar Birliği (TOBB) sanayi veri tabanında yer alan çimento sanayii istihdam verileri, TÜRKÇİMENTO (TÇMB)'dan dan alınan çimento sanayiinde yerel birim sayısı, Türkiye İstatistik Kurumu (TÜİK) Sanayi ve Hizmet İstatistikleri veri tabanından Düzey-2 Bölgeleri bazında toplam istihdam ve toplam yerel birim sayısı, Türkiye genelinde toplam istihdam ve toplam yerel birim sayısı verileridir.

Sanayi kollarının yoğunlaşma veya yığılma düzeylerinin tespit edilmesinde sanayi girişim sayısı, katma değer, üretim değerleri, ihracat değerleri ve istihdam değerleri kullanılmaktadır (Sungur, 2015:321). Sanayi kuruluşları yüksek kazanç sağlayabilecekleri bölgelerde yer seçimi yapma eğilimi gösterirler. Bu sebeple, yerel birim sayısı ya da girişim sayısı sanayi kümelenmesi tespitinde önemli bir göstergedir. Üretilen mal ve hizmet miktarı doğrudan istihdam ile ilgili olup ve yoğunlaşmayı en iyi yansıtan göstergedir (Urhan \& Sandal, 2019:176). Bu çalışmada diğer birçok çalışmada olduğu gibi istatistiksel verilerin kısıtlı olmasından dolayı girişim sayıları ve istihdam verileri kullanılmıştır. Bu veriler aracılığıyla, çimento sanayiinin Türkiye' de yoğunlaşma endeksinin hesaplanmasında Yoğunlaşma Katsayısı (Location Quatient) yöntemi kullanılmıştır. 
Lokasyon Katsayısı (LQ), istihdam oranları gibi yerel olan özelliklerin ulusal özelliklerle karşılaştırılmasını sağlayan bir tekniktir. Bu teknik, 1940'tan beri bölgesel iktisatçılar ve ekonomik coğrafyacılar tarafından yaygın olarak kullanılmaktadır (Moineddin vd., 2003:249). Yoğunlaşma Katsayısı, sanayi kolunun herhangi bir bölgede yoğunluğunu, ilgili sanayi kolunun yoğunluğuna oranlanması ile hesaplanmaktadır. Dolayısıyla, bölgede ilgili sanayi kolunda yoğunlaşma olup olmadığının tespit edilmesinde kullanılmaktadır. Yoğunlaşma Katsayısı aşağıda yer alan formül aracılığı ile hesaplanmaktadır:

$$
L Q=\left(\frac{\boldsymbol{e i r}}{E r}\right) /\left(\frac{E i n}{E n}\right)
$$

$$
\begin{array}{ll}
\text { eir } & \text { : i sektörünün } \mathrm{r} \text { bölgedeki/ildeki istihdamı } \\
\text { Er } & : \text { r bölgedeki/ildeki toplam istihdamı } \\
\text { Ein } & : \text { i sektörünün } \mathrm{n} \text { referans bölgedeki/ülkedeki istihdamı } \\
\text { En } & : \text { referans } \mathrm{n} \text { bölgedeki/ülkedeki toplam istihdamı }
\end{array}
$$

Formülde; eir, $i$ sektörünün $r$ bölgedeki/ ildeki istihdamını, Er, $r$ bölgedeki toplam istihdamı, Ein, i sektörünün $n$ referans bölgedeki/ülkedeki istihdamını, En, referans n bölge ya da ülkedeki toplam istihdamı ifade etmektedir (Isserman, 1977: 34). Yoğunlaşma Katsayısı; belli bir sektörün belli bir bölgedeki istihdam oranının (ei/ $\mathrm{e}$ ), o sektörün ülke genelindeki istihdam oranına (Ei/ $\Sigma \mathrm{E})$ bölünmesi ile kullanılan denklem, aritmetik hesaplama yöntemidir (Bayraktutan vd., 2012:63).

Yoğunlaşma katsayısı, LQ'nın 1.25'den büyük olması ilgili sanayi kolunun bölgede yoğunlaşmış olduğunu gösterir (Yardımcı, 2014: 59). LQ değerlerine bağlı olarak beş grupta değerlendirme yapılmıştır. Tablo 2'de verilen her gruptaki LQ değeri için, alt sınır 0,50, üst sınır 1,25 olarak belirlenmiştir.

Tablo 2: Yoğunlaşma Katsayısı Grup Değerleri ve Kümelenme Durumu

\begin{tabular}{ccc}
\hline \hline Grup & LQ Değeri & Kümelenme Durumu \\
\hline 1 & 0,50 'den küçük & Yok \\
2 & $0,50-0,99$ aras1 & Oüşük \\
3 & $1,00-1,09$ aras1 & Yüksek \\
4 & $1,10-1,24$ aras1 & Çok Yüksek \\
\hline
\end{tabular}

Kaynakça: (Yardımcı, 2014: 59).

Yapılan lokasyon katsayısı analizleri, ArcGIS 10.8 programında tekrar analiz edilerek, çimento sanayiinde yoğunluk katsayısı oranlarına göre 2014 ve 2019 yıllarına ait yerel birim sayısı ve istihdam sayısına göre haritalandırma yapılmıştır.

\section{BULGULAR}

\subsection{Yerel Birim Sayısına Göre Yoğunlaşma Katsayısı ve Kümelenme}

Çimento sanayisi için lokasyon katsayısı tekniğine göre analiz edilen ilk parametre yerel birim sayısıdır. Buna göre 2014 yılında; dört bölge haricinde, diğer bölgelerin endeks değerleri 1.25'in üzerindedir. 2019 y1lında 22 bölge 1.25 'in üzerinde endeks değerine sahip iken 2014'te çok yüksek olan iki bölge 2019'da yüksek potansiyele sahip bölge durumuna dönüşmüştür.

Şekil 1.’de görüldüğü üzere 2014 yılına ait yerel birim sayısına göre yoğunlaşma katsayısı haritası oluşturulmuştur. Haritada kırmızı renkte gösterilen bölgeler çimento sanayiinde en fazla yoğunlaşmanın görüldüğü bölgelerdir. Tablo 2.'de kümelenme gruplarına göre TR82 (Çankırı, Kastamonu, Sinop), TR22 (Çanakkale, Balıkesir) bölgelerinde kümelenme 'yok', TR71 (Aksaray, Kırıkkale, Niğde, Kırşehir, Nevşehir), TRB1 (Elazı̆̆g, Malatya, Tunceli, Bingöl) bölgelerinde ise 'yüksek' kümelenme potansiyeli, geriye kalan bölgelerde 'çok yüksek' kümelenme olduğu söylenebilir. Ancak yapılan analizde Türkiye çimento sanayinin fazla kümelenme gösterdiği belirlenerek yoğunlaşma katsayısı 1.25 'ten uzaklaştıkça kümelenmenin daha fazla olduğu bölgeler daha da koyulaşarak kırmızı renge dönüştüğü tespit edilmiştir. 


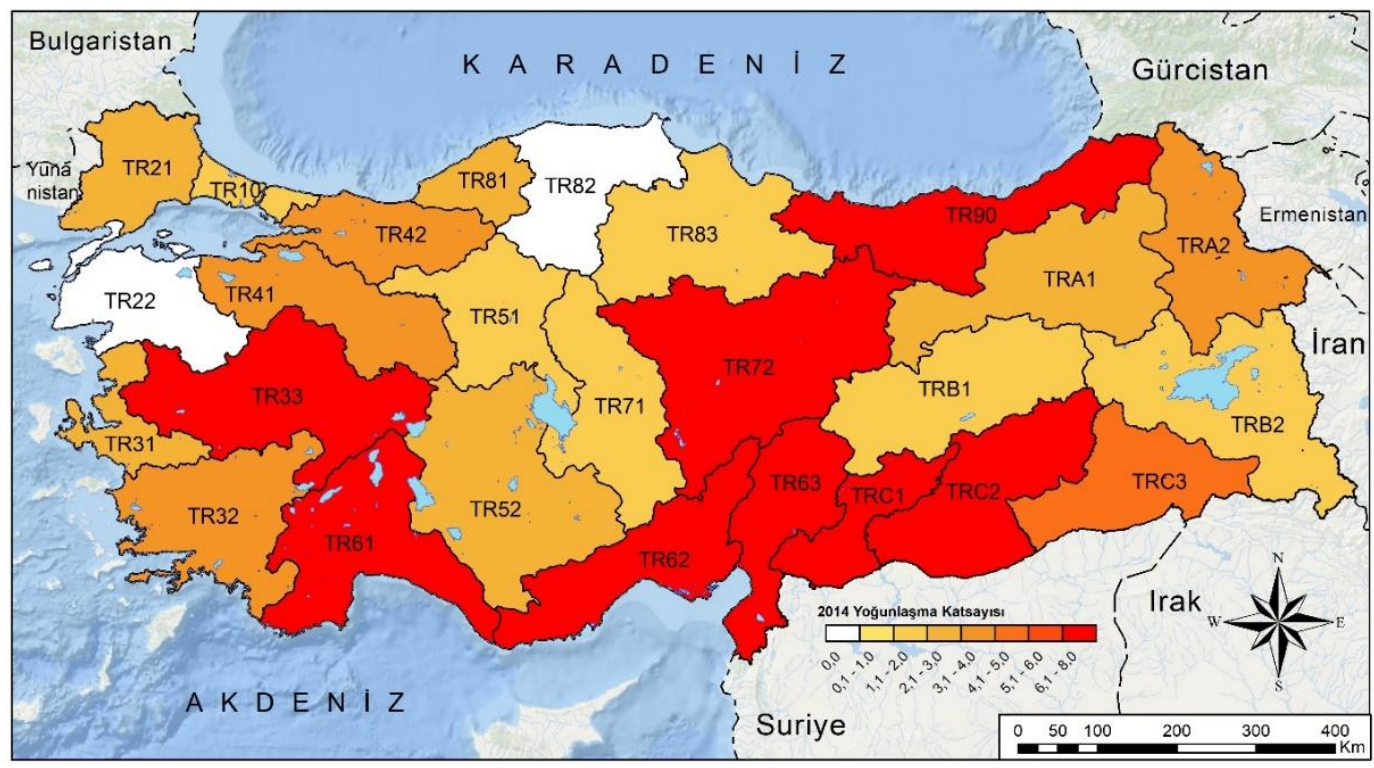

Şekil 1: 2014 Yılı Türkiye Düzey-2 Bölge Ölçeğinde Çimento Sanayiinin Yerel Birim Sayısına Göre Yoğunlaşma Katsayısı Haritas1

2014 yılında yerel birim sayısına göre; TR10 İstanbul Alt Bölgesinin endeks değerinin 'çok yüksek' olduğu kümelenme durumu, 2019 yılında endeks değerinde düşüş gerçekleşerek 'orta' kümelenme durumuna geçtiğgi gözlenmiştir. 2014 y1lında TRB1 (Elazığg, Malatya, Tunceli, Bingöl) bölgesinin 'yüksek' olan kümelenme durumu 2019 y1lında 'çok yüksek' kümelenme şeklinde lokasyon katsayısı artmıştır. 2014 yılında TR22 (Çanakkale, Balıkesir) ve TR82 (Çankırı, Kastamonu, Sinop) bölgelerinin kümelenme durumunun 'yok' olduğu tespit edilmiş ve 2019 yılında değişmediği belirlenmiştir (Tablo 3. ve Tablo 4.).

Yapılan analizde 2014 yılında, yerel birim sayısına göre 1.25 'çok yüksek’ referansının çok üzerinde yoğunlaşma olduğu görülmüş, bu çalışmada yoğunluğun en fazla olduğu bölgeleri belirlemek amacıyla 5,5 (Şekil 1.'de kırmızı renkte gösterilen bölgeler) ve üzerinde yoğunluk katsayısına sahip bölgeler TR33 (Afyon, Manisa, Uşak, Kütahya), TR61(Isparta, Antalya, Burdur), TR62 (Mersin, Adana), TR63 (Osmaniye, Kahramanmaraş, Hatay), TR72 (Yozgat, Sivas, Kayseri), TR90 (Ordu, Giresun, Gümüşhane, Trabzon, Rize, Artvin), TRC1 (Adıyaman, Kilis, Gaziantep) ve TRC2 (Diyarbakır, Şanlıurfa) olarak tespit edilmiştir (Tablo 3). Özellikle TR72 (Yozgat, Sivas, Kayseri) '9,07' ve TRC2 (Diyarbakır, Şanlıurfa) '8,88' yerel birim yoğunlaşma katsayısı ile 2014 yılında en çok kümelenme gösteren bölgeler olmuştur. TR22 (Çanakkale, Balıkesir) '0’ ve TR82 (Çankırı, Kastamonu, Sinop) '0’ yerel birim sayısı yoğunlaşma katsayısına göre hiç kümelenme olmayan bölgelerdir.

Tablo 3: 2014 Yılı Türkiye Düzey-2 Bölge Ölçeğinde Çimento Sanayiinin Yerel Birim Sayısına Göre Yoğunlaşma Katsayısı Dağılımı

\begin{tabular}{cllll}
\hline \hline Kod & Düzey 2 Bölge & iller & $\begin{array}{l}\mathbf{2 0 1 4} \\
\text { Yoğunlaşma } \\
\text { Katsayıs }\end{array}$ & Kümelenme Durumu \\
\hline TR10 & İstanbul Alt Bölgesi & İstanbul & 1,25 & Çok Yüksek \\
TR21 & Tekirdă̆ Alt Bölgesi & Tekirdağ & 2,27 & Çok Yüksek \\
TR22 & Balıkesir Alt Bölgesi & Balıkesir, Çanakkale & 0 & Yok \\
TR31 & İzmir Alt Bölgesi & İzmir & 2,41 & Çok Yüksek \\
TR32 & Aydın Alt Bölgesi & Aydın, Denizli, Muğla & 3,66 & Çok Yüksek \\
TR33 & Manisa Alt Bölgesi & Afyon, Manisa, Uşak, Kütahya & 6,61 & Çok Yüksek \\
TR41 & Bursa Alt Bölgesi & Bilecik, Bursa, Eskişehir & 3,75 & Çok Yüksek \\
TR42 & Kocaeli Alt Bölgesi & Kocaeli, Sakarya, Düzce, Bolu Yalova & 3,66 & Çok Yüksek \\
TR51 & Ankara Alt Bölgesi & Ankara & 1,26 & Çok Yüksek
\end{tabular}




\begin{tabular}{|c|c|c|c|c|}
\hline TR52 & Konya Alt Bölgesi & Karaman, Konya & 2,15 & Çok Yüksek \\
\hline TR61 & Antalya Alt Bölgesi & Isparta, Antalya, Burdur & 6,9 & Çok Yüksek \\
\hline TR62 & Adana Alt Bölgesi & Mersin, Adana & 7,87 & Çok Yüksek \\
\hline TR63 & Hatay Alt Bölgesi & Osmaniye, Hatay, Kahramanmaraş & 7,73 & Çok Yüksek \\
\hline TR71 & Kırıkkale Alt Bölgesi & Kırıkkale, Aksaray, Niğde, Nevşehir, Kırşehir & 1,17 & Yüksek \\
\hline TR72 & Kayseri Alt Bölgesi & Kayseri, Sivas, Yozgat & 9,07 & Çok Yüksek \\
\hline TR81 & Zonguldak Alt Bölgesi & Zonguldak, Karabük, Bartın & 2,82 & Çok Yüksek \\
\hline TR82 & Kastamonu Alt Bölgesi & Kastamonu, Çankırı, Sinop & 0 & Yok \\
\hline TR83 & Samsun Alt Bölgesi & Samsun, Tokat, Çorum, Amasya & 1,43 & Çok Yüksek \\
\hline TR90 & Trabzon Alt Bölgesi & $\begin{array}{l}\text { Trabzon, Ordu, Giresun, Rize, Artvin, } \\
\text { Gümüşhane }\end{array}$ & 6,56 & Çok Yüksek \\
\hline TRA1 & Erzurum Alt Bölgesi & Erzurum, Bayburt, Erzincan, & 2,39 & Çok Yüksek \\
\hline TRA2 & Ağrı Alt Bölgesi & Kars, Ağrı, Ardahan, Iğdır & 3,88 & Çok Yüksek \\
\hline TRB1 & Malatya Alt Bölgesi & Elazığ, Malatya, Tunceli, Bingöl & 1,16 & Yüksek \\
\hline TRB2 & Van Alt Bölgesi & Muş, Van, Hakkâri, Bitlis & 1,96 & Çok Yüksek \\
\hline $\mathrm{TRC} 1$ & Gaziantep Alt Bölgesi & Adıyaman, Kilis, Gaziantep, & 6,67 & Çok Yüksek \\
\hline TRC2 & Şanlıurfa Alt Bölgesi & Diyarbakır, Şanlıurfa & 8,88 & Çok Yüksek \\
\hline TRC3 & Mardin Alt Bölgesi & Batman, Mardin, Siirt, Şırnak & 4,7 & Çok Yüksek \\
\hline
\end{tabular}

Şekil 2.'de yer alan haritada 2019 yılına ait yerel birim sayısına göre yoğunlaşma katsayısı gösterilmektedir. Haritada kırmızı renkte gösterilen bölgeler 2019 yılında çimento sanayiinde en fazla yoğunlaşmanın görüldüğ̈̈ bölgelerdir. Yapılan analizde çimento sanayiinin Türkiye'de çok fazla kümelendiği belirlenerek, haritada TR90 (Ordu, Trabzon, Rize, Giresun, Gümüşhane, Artvin), TR72 (Sivas, Yozgat, Kayseri), TR63 (Osmaniye, Hatay, Kahramanmaraş), TR62 (Adana, Mersin) ve TRC2 (Şanlıurfa, Diyarbakır) bölgeleri en fazla kümelenen bölgelerdir.

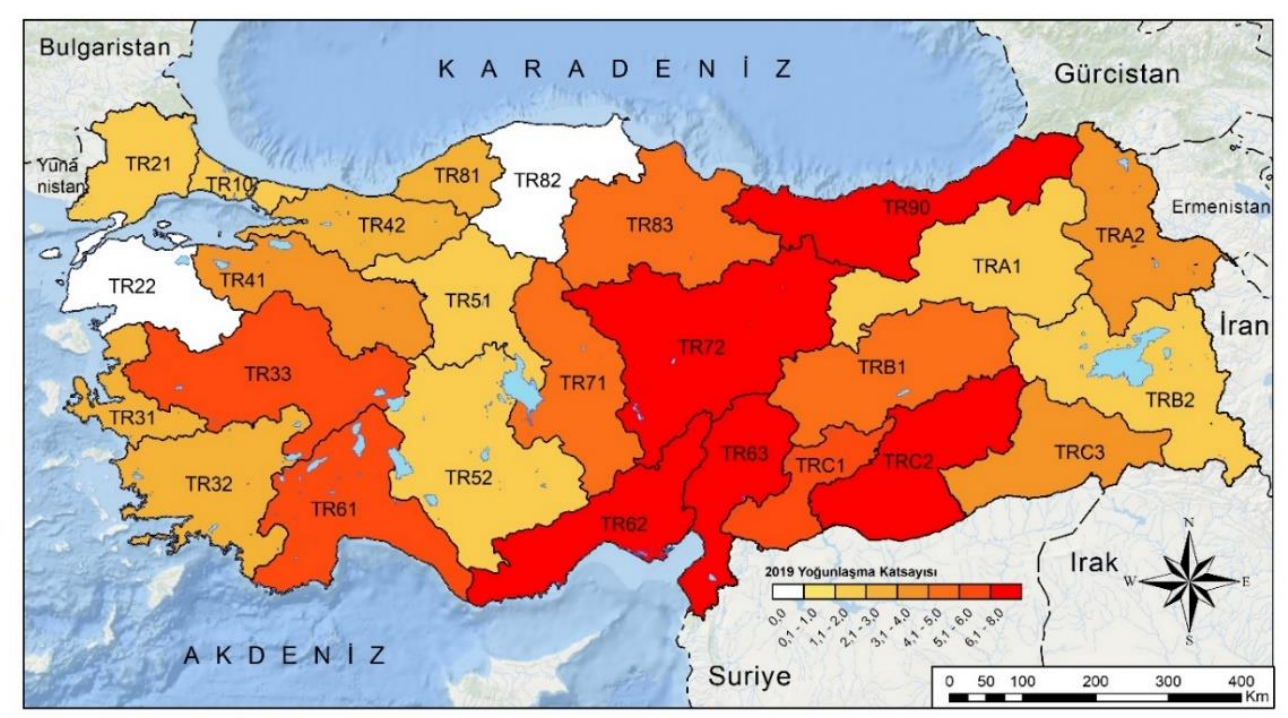

Şekil 2: 2019 Yılı Türkiye Düzey-2 Bölge Ölçeğinde Çimento Sanayiinin Yerel Birim Sayısına Göre Yoğunlaşma Katsayısı Haritas1

2019 yılında 5,5'in üzerinde değere sahip yerel birim sayısına göre çok fazla yoğunlaşan bölgeler; TR62 (Mersin, Adana); 6,68, TR63 (Osmaniye, Kahramanmaraş, Hatay); 7,03, TR72 Yozgat Kayseri, Sivas); 7,12, TR90 (Ordu, Giresun, Gümüşhane, 
Trabzon, Rize, Artvin); 7,78, TRC2 (Diyarbakır, Şanlıurfa); 7,26 bölgeleridir. TR10 (İstanbul) 1,09 yoğunlaşma katsayısı ile kümelenme durumu 'orta', TR22 (Çanakkale, Balıkesir) ve TR82 (Çankırı, Sinop, Kastamonu) '0' yoğunlaşma katsayısı ile kümelenme durumu 'yok' şeklinde çıkan analiz sonuçları dışında kalan bölgeler 'çok yüksek' kümelenme durumu gösteren bölgelerdir (Tablo 4).

Tablo 4: 2019 Yılı Türkiye Düzey-2 Bölge Ölçeğinde Çimento Sanayiinin Yerel Birim Sayısına Göre Yoğunlaşma Katsayısı Dağılımı

\begin{tabular}{|c|c|c|c|c|}
\hline Kod & Düzey 2 Bölge & İller & $\begin{array}{l}2019 \text { Yoğunlaşma } \\
\text { Katsayısı }\end{array}$ & Kümelenme Durumu \\
\hline TR10 & İstanbul Alt Bölgesi & İstanbul & 1,09 & Orta \\
\hline TR21 & Tekirdağ Alt Bölgesi & Tekirdağ & 1,71 & Çok Yüksek \\
\hline TR22 & Balıkesir Alt Bölgesi & Çanakkale, Balıkesir & 0 & Yok \\
\hline TR31 & İzmir Alt Bölgesi & İzmir & 2,05 & Çok Yüksek \\
\hline TR32 & Aydın Alt Bölgesi & Muğla, Aydın, Denizli & 2,86 & Çok Yüksek \\
\hline TR33 & Manisa Alt Bölgesi & Manisa, Afyonkarahisar, Uşak, Kütahya & 5,21 & Çok Yüksek \\
\hline TR41 & Bursa Alt Bölgesi & Bilecik, Bursa, Eskişehir & “" & Çok Yüksek \\
\hline TR42 & Kocaeli Alt Bölgesi & Kocaeli, Sakarya, Düzce, Bolu Yalova & 2,89 & Çok Yüksek \\
\hline TR51 & Ankara Alt Bölgesi & Ankara & 1,15 & Yüksek \\
\hline TR52 & Konya Alt Bölgesi & Konya, Karaman & 1,73 & Çok Yüksek \\
\hline TR61 & Antalya Alt Bölgesi & Antalya, Isparta, Burdur & 5,41 & Çok Yüksek \\
\hline TR62 & Adana Alt Bölgesi & Adana, Mersin & 6,68 & Çok Yüksek \\
\hline TR63 & Hatay Alt Bölgesi & Hatay, Kahramanmaraş, Osmaniye & 7,03 & Çok Yüksek \\
\hline TR71 & Kırıkkale Alt Bölgesi & $\begin{array}{l}\text { Kırıkkale, Aksaray, Niğde, Nevşehir, } \\
\text { Kırşehir }\end{array}$ & 4,2 & Çok Yüksek \\
\hline TR72 & Kayseri Alt Bölgesi & Kayseri, Sivas, Yozgat & 7,12 & Çok Yüksek \\
\hline TR81 & Zonguldak Alt Bölgesi & Zonguldak, Karabük, Bartın & 2,32 & Çok Yüksek \\
\hline TR82 & Kastamonu Alt Bölgesi & Sinop, Kastamonu, Çankırı & 0 & Yok \\
\hline TR83 & Samsun Alt Bölgesi & Tokat, Amasya, Samsun, Çorum & 4,13 & Çok Yüksek \\
\hline TR90 & Trabzon Alt Bölgesi & $\begin{array}{l}\text { Ordu, Trabzon, Artvin, Giresun, Rize, } \\
\text { Gümüşhane }\end{array}$ & 7,78 & Çok Yüksek \\
\hline TRA1 & Erzurum Alt Bölgesi & Erzincan, Erzurum, Bayburt & 1,89 & Çok Yüksek \\
\hline TRA2 & Ağrı Alt Bölgesi & Kars, Ağrı, Ardahan, Iğdır & 3,13 & Çok Yüksek \\
\hline TRB1 & Malatya Alt Bölgesi & Elazığ, Malatya, Tunceli, Bingöl & 4,62 & Çok Yüksek \\
\hline TRB2 & Van Alt Bölgesi & Van, Bitlis, Hakkâri, Muş & 1,58 & Çok Yüksek \\
\hline TRC1 & Gaziantep Alt Bölgesi & Kilis, Gaziantep, Adiyaman & 5,36 & Çok Yüksek \\
\hline TRC2 & Şanlıurfa Alt Bölgesi & Diyarbakır, Şanlıurfa & 7,26 & Çok Yüksek \\
\hline TRC3 & Mardin Alt Bölgesi & Batman, Şırnak, Mardin, Siirt & 3,39 & Çok Yüksek \\
\hline
\end{tabular}

2014 çimento sanayiinin yerel birim sayısına göre yoğunlaşma katsayısı dağılımı değerleri ve 2019 çimento sanayiinin yerel birim sayısına göre yoğunlaşma katsayısı dağılımı değerleri karşılaştırıldığında; yerel birim sayısına göre 2014 yılında en 
fazla yoğunlaşma TR90 (Ordu, Trabzon, Giresun, Artvin, Gümüşhane, Rize), TR72 (Yozgat, Kayseri, Sivas), TR61 (Antalya, Isparta, Burdur), TR62 (Adana, Mersin), TR63 (Hatay, Kahramanmaraş, Osmaniye), TR33 (Manisa, Afyon, Kütahya, Uşak), TRC1 (Gaziantep, Adıyaman, Kilis), TRC2 (Şanlıurfa, Diyarbakır) bölgelerinde gerçekleşirken, 2019 yılında TR90 (Ordu, Trabzon, Rize, Giresun, Gümüşhane, Artvin,), TR72 (Kayseri, Sivas, Yozgat), TR62 (Adana, Mersin), TR63 (Osmaniye, Hatay, Kahramanmaraş), TRC2 (Şanlıurfa, Diyarbakır) bölgelerinde en fazla yoğunlaşma gerçekleşmiştir. 2014 yılında, TR61 (Burdur, Isparta, Antalya), TR33 (Afyon, Manisa, Uşak, Kütahya), TRC1 (Kilis, Adıyaman, Gaziantep) bölgelerinde yerel birim katsayısı daha fazla iken, 2019 yılında yoğunluk katsayısında azalma gerçekleşmiştir. Yerel birim sayısı yoğunlaşma katsayısı 2014 yılında; TR10 (İstanbul) 'çok yüksek' kümelenmeden 'orta' kümelenmeye, TR51 (Ankara) 'çok yüksek' kümelenmeden 'yüksek' kümelenmeye, TR71 (Kırıkkale, Aksaray, Niğde, Nevşehir, Kırşehir), TRB1 (Malatya, Elazı̆̆g, Bingöl, Tunceli) 'yüksek' kümelenmeden 'çok yüksek' kümelenme şeklinde değişiklik göstermiştir.

\section{2. İstihdama Göre Yoğunlaşma Katsayısı ve Kümelenme}

Çimento sanayii için lokasyon katsayısı tekniğine göre analiz edilen ikinci gösterge olan istihdam katsayısı yoğunlaşmayı en iyi yansıtan göstergedir. Buna göre; 2014 yılında bu sanayi kolunda 2 bölge dışında kalan bölgelerin endeks değeri 1.25'in üzerindedir. 2019 yılında ise; 8 bölge dışında kalan 18 bölgede yoğunlaşma fazladır. İstihdama göre yoğunlaşma, 2014 yılına göre 2019 yılında azalma gerçekleşmiştir (Tablo 5 ve Tablo 6). TRC3 (Mardin, Batman, Şırnak, Siirt) ve TR62 (Adana, Mersin) kümelenmeleri 2014 ve 2019'da oldukça fazla olup kümelenme bakımından yoğunluk katsayıları pek değişmeyerek haritalarda renkleri aynı kalmıştır (Şekil 3 ve Şekil 4).

Şekil 3'te yer alan haritada görüldüğü üzere 2014 yılı istihdama göre en fazla yoğunluk; TR81 Karabük, Bartın, Zonguldak), TR52 (Karaman, Konya), TR62 (Mersin, Adana), TRA1 (Bayburt, Erzincan, Erzurum), TRA2 (Kars, Iğdır, Ardahan, Ağrı), TRC3 (Batman, Şırnak, Siirt, Mardin) bölgelerindedir.

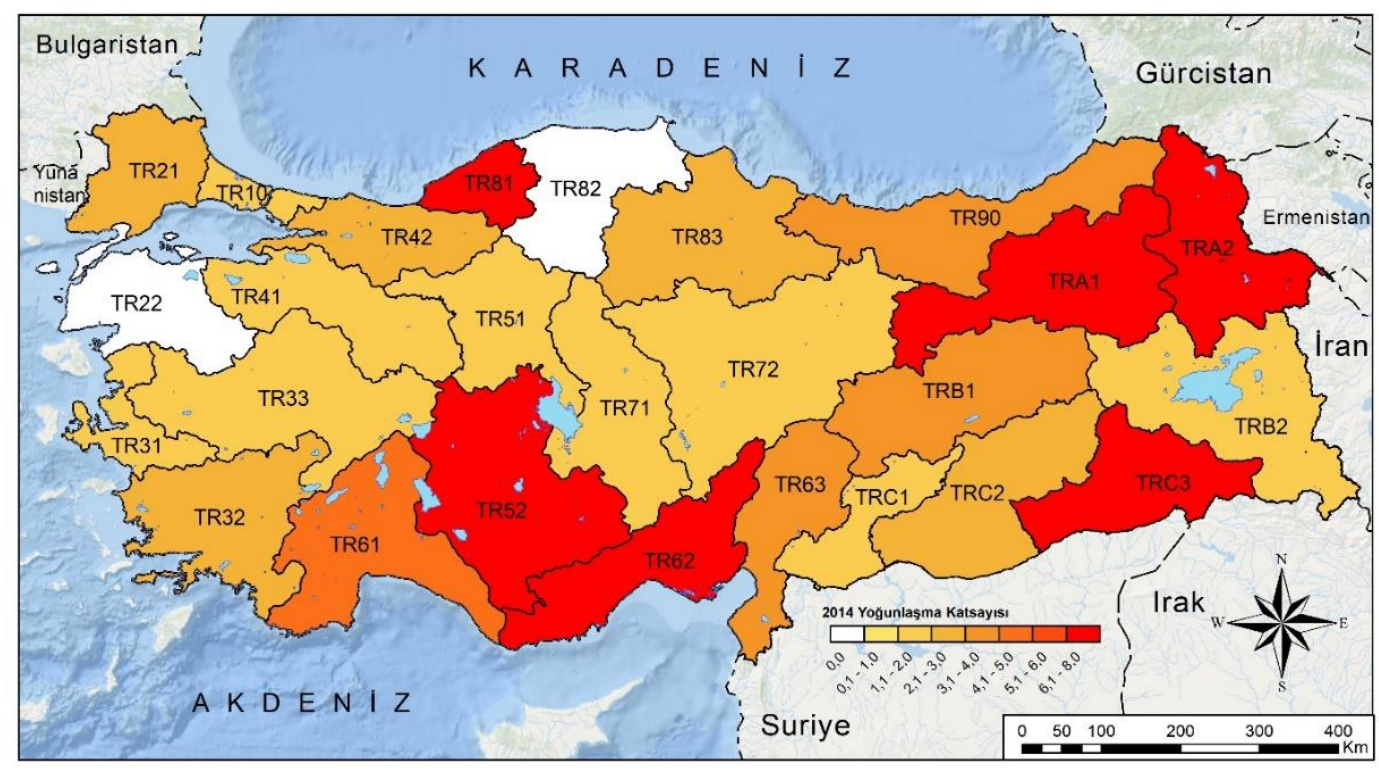

Şekil 3: 2014 Yılı Türkiye Düzey-2 Bölge Ölçeğinde Çimento Sanayiinin İstihdama Göre Yoğunlaşma Katsayısı Haritası

Yapılan yoğunlaşma katsayısı analizine göre, istihdam bakımından 2014 yılında; hiç kümelenme göstermeyen bölgeler TR22 (Balıkesir, Çanakkale) ve TR82 (Kastamonu, Çankırı, Sinop) bölgeleri, 1.25-5.50 arasında kümelenme gösteren 'çok yüksek’ bölgeler; TR10 (İstanbul), TR21 (Tekirdağ), TR31 (İzmir), TR32 (Muğla, Aydın, Denizli), TR33 (Afyon, Manisa, Uşak, Kütahya,), TR41 (Bilecik, Bursa, Eskişehir), TR42 (Sakarya, Kocaeli, Düzce, Yalova, Bolu), TR51 (Ankara), TR61 (Burdur, Antalya, Isparta), TR63 (Osmaniye, Hatay, Kahramanmaraş), TR71 (Aksaray, Kırıkkale, Kırşehir, Niğde, Nevşehir), TR72 (Sivas, Yozgat, Kayseri,), TR83 (Samsun, Tokat, Çorum, Amasya), TR90 (Trabzon, Ordu, Giresun, Rize, Artvin, Gümüşhane), TRB1 (Malatya, Elazı̆̆g, Bingöl, Tunceli), TRB2 (Van, Muş, Bitlis, Hakkâri) TRC2 (Şanlıurfa, Diyarbakır) bölgeleridir (Tablo 5). 5,50 ve üzeri kümelenme gösteren bölgeler; TR52 (Konya, Karaman), TR62 (Adana, Mersin), TR81 (Zonguldak, Karabük, Bartın), TRA1 (Erzurum, Erzincan, Bayburt), TRA2 (Ăgrı, Kars, Iğdır, Ardahan), TRC3 (Mardin, Batman, Şırnak, Siirt) bölgeleridir. 
Tablo 5: 2014 Yılı Türkiye Düzey-2 Bölge Ölçeğinde Çimento Sanayiinin İstihdama Göre Yoğunlaşma Katsayısı Dağılımı

\begin{tabular}{|c|c|c|c|c|}
\hline Kod & Düzey 2 Bölge & iller & $\begin{array}{l}2014 \\
\text { Yoğunlaşma } \\
\text { Katsayısı }\end{array}$ & Kümelenme Durumu \\
\hline TR10 & İstanbul Alt Bölgesi & İstanbul & 1,52 & Çok Yüksek \\
\hline TR21 & Tekirdağ Alt Bölgesi & Tekirdağ & 2,05 & Çok Yüksek \\
\hline TR22 & Balıkesir Alt Bölgesi & Balıkesir, Çanakkale & 0 & Yok \\
\hline TR31 & İzmir Alt Bölgesi & İzmir & 1,33 & Çok Yüksek \\
\hline TR32 & Aydın Alt Bölgesi & Aydın, Denizli, Muğla & 2,38 & Çok Yüksek \\
\hline TR33 & Manisa Alt Bölgesi & Afyon, Manisa, Uşak, Kütahya & 1,46 & Çok Yüksek \\
\hline TR41 & Bursa Alt Bölgesi & Bilecik, Bursa, Eskişsehir & 1,55 & Çok Yüksek \\
\hline TR42 & Kocaeli Alt Bölgesi & Sakarya, Kocaeli, Yalova, Düzce, Bolu & 2,37 & Çok Yüksek \\
\hline TR51 & Ankara Alt Bölgesi & Ankara & 1,28 & Çok Yüksek \\
\hline TR52 & Konya Alt Bölgesi & Karaman, Konya & 8,36 & Çok Yüksek \\
\hline TR61 & Antalya Alt Bölgesi & Burdur, Antalya, Isparta & 4,51 & Çok Yüksek \\
\hline TR62 & Adana Alt Bölgesi & Adana, Mersin & 6,2 & Çok Yüksek \\
\hline TR63 & Hatay Alt Bölgesi & Osmaniye, Hatay, Kahramanmaraş & 3,33 & Çok Yüksek \\
\hline TR71 & Kırıkkale Alt Bölgesi & $\begin{array}{l}\text { Aksaray, Kırıkkale, Nevşehir, Kırşehir, } \\
\text { Niğde }\end{array}$ & 1,26 & Çok Yüksek \\
\hline TR72 & Kayseri Alt Bölgesi & Yozgat, Kayseri, Sivas & 1,51 & Çok Yüksek \\
\hline TR81 & Zonguldak Alt Bölgesi & Bartın, Zonguldak, Karabük & 9,57 & Çok Yüksek \\
\hline TR82 & Kastamonu Alt Bölgesi & Sinop, Kastamonu, Çankırı & 0 & Yok \\
\hline TR83 & Samsun Alt Bölgesi & Amasya, Tokat, Samsun, Çorum & 2,57 & Çok Yüksek \\
\hline TR90 & Trabzon Alt Bölgesi & $\begin{array}{l}\text { Ordu, Trabzon, Rize, Giresun, Gümüşhane, } \\
\text { Artvin }\end{array}$ & 3,99 & Çok Yüksek \\
\hline TRA1 & Erzurum Alt Bölgesi & Bayburt, Erzincan, Erzurum & 7,78 & Çok Yüksek \\
\hline TRA2 & Ağrı Alt Bölgesi & Ardahan, Kars, Ağrı, Iğdır & 6,73 & Çok Yüksek \\
\hline TRB1 & Malatya Alt Bölgesi & Tunceli, Malatya, Bingöl, Elazı̆̆ & 3,09 & Çok Yüksek \\
\hline TRB2 & Van Alt Bölgesi & Van, Muş, Bitlis, Hakkâri & 1,87 & Çok Yüksek \\
\hline TRC1 & Gaziantep Alt Bölgesi & Kilis, Adıyaman, Gaziantep, & 1,57 & Çok Yüksek \\
\hline TRC2 & Şanlıurfa Alt Bölgesi & Şanlıurfa, Diyarbakır & 2,54 & Çok Yüksek \\
\hline TRC3 & Mardin Alt Bölgesi & Siirt, Mardin, Şırnak, Batman & 8,7 & Çok Yüksek \\
\hline
\end{tabular}

Şekil 4.'te yer alan haritada görüldüğü üzere istihdama göre en fazla yoğunluk 2019 yılında; TR62 (Adana, Mersin) ve TRC3 (Mardin, Batman, Şırnak, Siirt) bölgelerinde olup ve bu bölgeler kırmızı renkte gösterilmiştir. TR22 (Çanakkale, Balıkesir) ve TR82 (Sinop, Çankırı, Kastamonu) bölgelerinde kümelenme gerçekleşmezken, TR71 (Aksaray, Kırıkkale, Niğde, Nevşehir, Kırşehir), TRA1 (Bayburt, Erzurum, Erzincan), TRA2 (Ardahan, Kars, Iğdır, Ağrı), TRC1 (Kilis, Adıyaman, 
Gaziantep) bölgelerinde 'orta' kümelenme, TR33 (Kütahya, Manisa, Uşak, Afyon), TR81 (Bartın, Zonguldak, Karabük) bölgelerinde 'yüksek' kümelenme gerçekleşmiştir. Geriye kalan 16 bölgede ise yine 'çok yüksek' kümelenme gerçekleşmiştir.

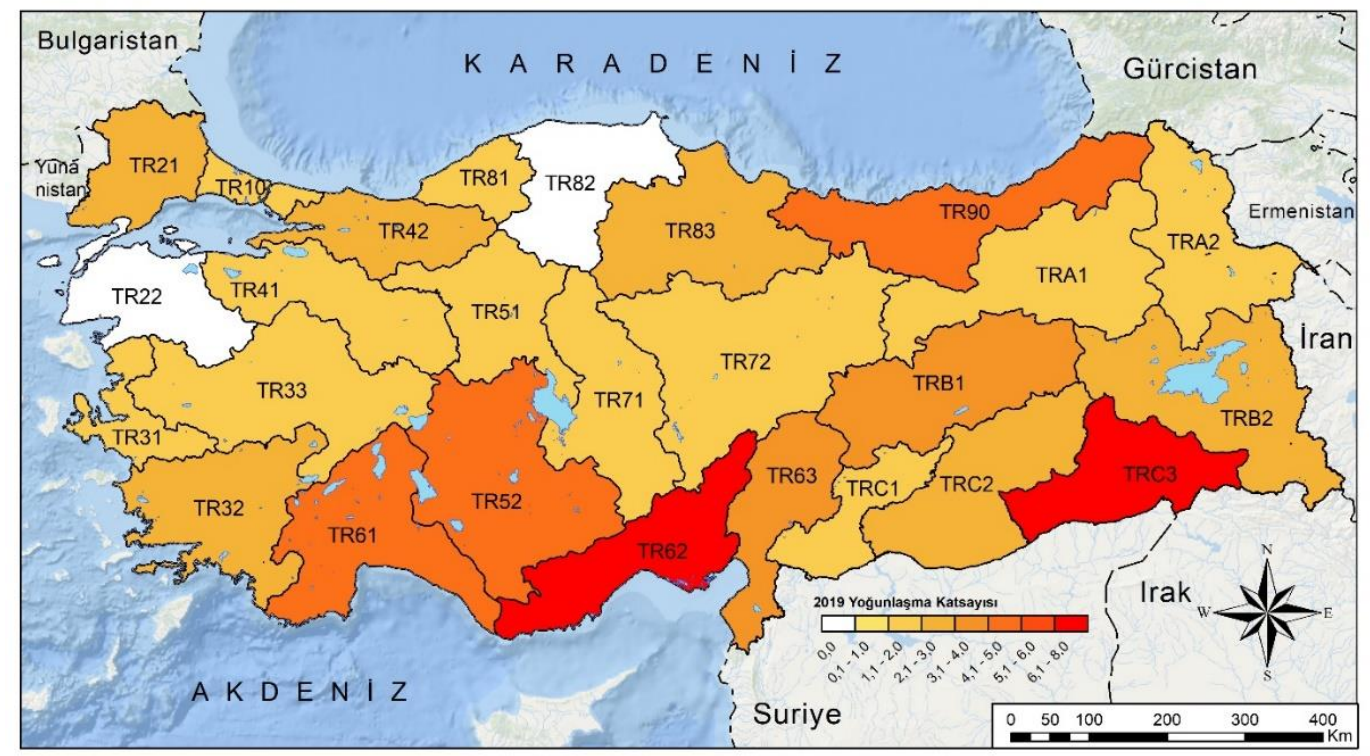

Şekil 4: 2019 Yılı Türkiye Düzey-2 Bölge Ölçeğinde Çimento Sanayiinin İstihdama Göre Yoğunlaşma Katsayısı Haritası

2019 yılına ait istihdama göre yoğunlaşma katsayıları ve kümelenme durumları incelendiğinde (Tablo 6); en fazla yoğunluk gösteren bölgelerin, TR62 (Mersin, Adana) ve TRC3 (Şırnak, Batman, Mardin, Siirt) bölgeleri olduğu tespit edilmiştir. Bu iki bölgenin 2014 yılında da çok fazla yoğunlaşma katsayısı gösterdiği ancak TR81 (Karabük, Zonguldak, Bartın), TR52 (Karaman, Konya), TRA1 (Bayburt, Erzurum, Erzincan), TRA2 (Ardahan, Ağrı, Kars, Iğdır) bölgeleri çok fazla yüksekken 2019 yılında yoğunlaşma katsayısında düşüş gerçekleşmiştir. 2014 yılında, 26 bölgeden 24'ü 'çok yüksek' kümelenme durumunda iken, 2019 yılında 'çok yüksek' kümelenme durumu gösteren bölge sayısı 18'e düşmüştür.

Tablo 6: 2019 Y1lı Türkiye Düzey-2 Bölge Ölçeğinde Çimento Sanayiinde İstihdama Göre Yoğunlaşma Katsayısı

\begin{tabular}{|c|c|c|c|c|}
\hline Kod & Düzey 2 Bölge & İller & $\begin{array}{l}2019 \\
\text { Yoğunlaşma } \\
\text { Katsayısı }\end{array}$ & Kümelenme Durumu \\
\hline TR10 & İstanbul Alt Bölgesi & İstanbul & 1,57 & Çok yüksek \\
\hline TR21 & Tekirdağ Alt Bölgesi & Tekirdağ & 2,13 & Çok yüksek \\
\hline TR22 & Balıkesir Alt Bölgesi & Balıkesir, Çanakkale & 0 & Yok \\
\hline TR31 & İzmir Alt Bölgesi & İzmir & 1,29 & Çok Yüksek \\
\hline TR32 & Aydın Alt Bölgesi & Aydın, Denizli, Muğla & 2,69 & Çok Yüksek \\
\hline TR33 & Manisa Alt Bölgesi & Manisa, Afyonkarahisar, Uşak Kütahya & 1,22 & Yüksek \\
\hline TR41 & Bursa Alt Bölgesi & Bilecik, Bursa, Eskişehir & 1,57 & Çok Yüksek \\
\hline TR42 & Kocaeli Alt Bölgesi & Yalova, Kocaeli, Bolu, Sakarya, Düzce & 2,31 & Çok Yüksek \\
\hline TR51 & Ankara Alt Bölgesi & Ankara & 1,44 & Çok Yüksek \\
\hline TR52 & Konya Alt Bölgesi & Konya, Karaman & 4,61 & Çok Yüksek \\
\hline TR61 & Antalya Alt Bölgesi & Burdur, Antalya, Isparta & 4,5 & Çok Yüksek \\
\hline TR62 & Adana Alt Bölgesi & Adana, Mersin & 6,66 & Çok Yüksek \\
\hline
\end{tabular}




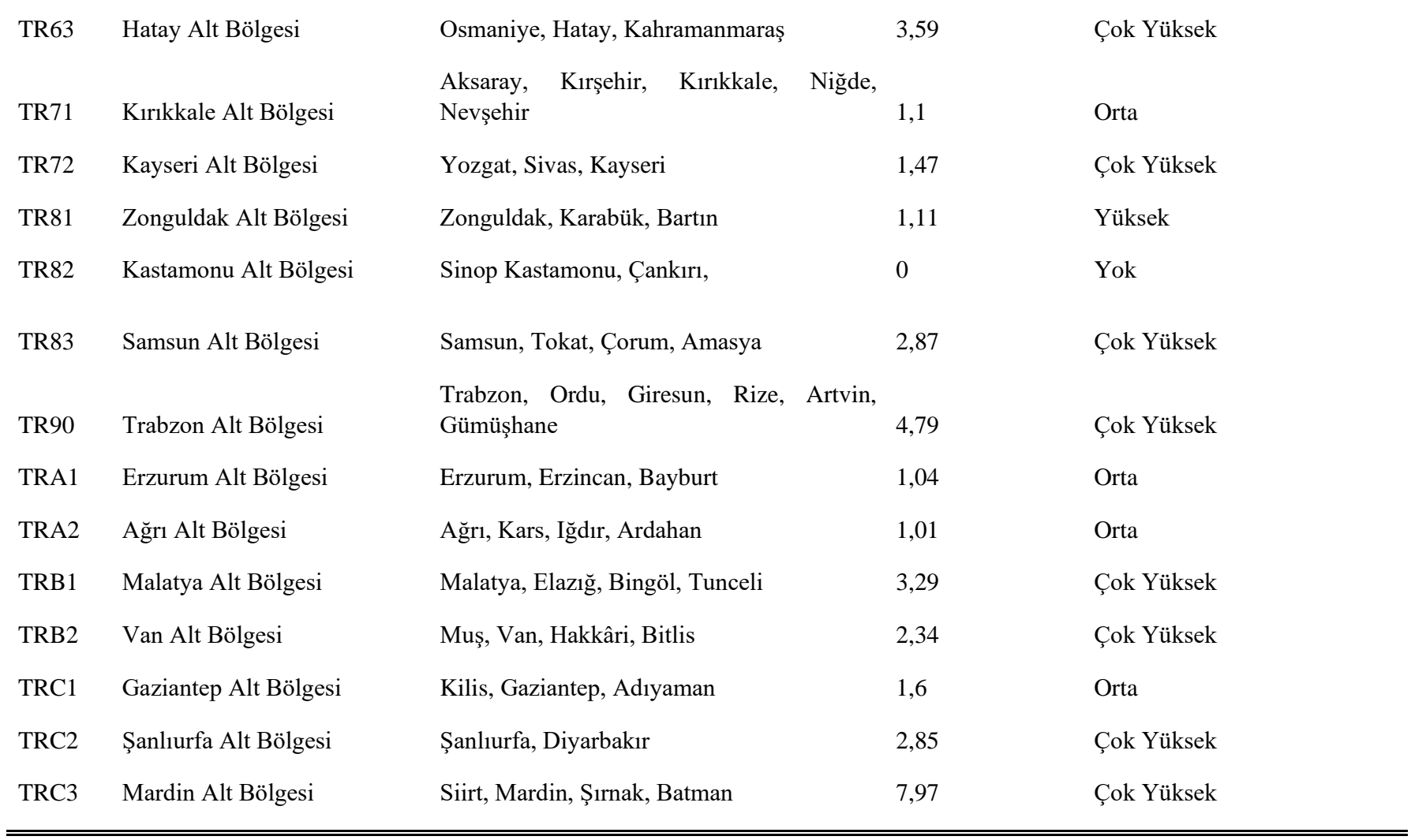

\section{SONUÇ}

Türkiye, küresel olarak çimento sektöründe güçlü ve söz sahibi ülkelerden biridir. Dünyanın altıncı büyük üreticisi ve ikinci büyük ihracatçısı olan Türkiye'nin küresel çimento pazarında payı gittikçe artmaktadır. Gerek ülke içinde gerekse ülke dışında çimentoya olan talebin artması nedeniyle üretim kapasitesi artmış, bu da fabrika ve istihdam sayılarında önemli artışlara yol açmıştır. Bu bağlamda Türkiye'de çimento sektörü hem yerel hem de bölgesel düzeyde kalkınmanın öncü sektörlerinden biri durumundadır.

Bu çalışma NACE Kod sistemine göre; NACE Rev2 23.51 kodlu çimento sanayii için çalışan sayısı ve yerel birim sayısı olmak üzere iki farklı parametre kullanılarak Türkiye'de Düzey-2 bölgelerine göre 2014 ve 2019 yıllarındaki mekânsal örüntüsünü ortaya koymaktadır. Bu amaç doğrultusunda, veriler bir sanayi kolunun yoğunlaşmayı en iyi yansıtan yöntemlerden biri olan yerelleşme katsayısı tekniği ile analiz edilmiştir. Buna göre 2014 yılında yerel birim sayısına (sanayi tesisi) göre yoğunlaşma katsayısı en yüksek bölgeler, TR72 Kayseri alt bölgesi (Yozgat, Kayseri, Sivas), TRC2 Şanlıurfa alt bölgesi (Şanlıurfa, Diyarbakır), TR62 Adana alt bölgesi (Mersin, Adana) ve TR63 Hatay alt bölgesi (Kahramanmaraş, Hatay, Osmaniye)' dir. 2019 yılında ise yerel birim sayısına göre yoğunlaşma katsayısının en yüksek olduğu bölgeler, TRC2 Şanlıurfa alt bölgesi (Diyarbakır, Şanlıurfa), TR90 Trabzon alt bölgesi (Ordu, Rize, Trabzon, Giresun, Gümüşhane Artvin), TR72 Kayseri alt bölgesi (Yozgat, Kayseri, Sivas) ve TR63 Hatay alt bölgesi (Hatay, Kahramanmaraş, Osmaniye)'dir. Buna göre Türkiye'de çimento sanayisi girişim sayısına göre en fazla Güneydoğu Anadolu Bölgesi, İç Anadolu Bölgesinin orta kesimleri, Akdeniz Bölgesinin doğusu ve Karadeniz Bölgesinin orta ve doğusunda yoğunluk göstermektedir. Şanlıurfa, Adana, Hatay, Kayseri, Trabzon gibi illerde çimento endüstrisinde tesis ve yatırım sayısında son yıllarda önemli bir artış yaşanmaktadır. İstanbul, Ankara gibi illerde ise son yıllarda çimento yatırımlarında ise bir durgunluk söz konusudur. Bu durgunluğun temel sebebi olarak söz konusu metropollerde inşaat sektöründe talep azlığı ve ekonomik krizlerin yarattığı olumsuzluklar sonucunda ortaya çıkan sektörel daralmadır. Diğer yandan çimento sektöründe üretim tesislerinin açılabilmesi için yüksek bir sermaye, zaman alıcı prosedürler ve yer seçimi ile ilgili detaylı ve nitelikli araştırmalara ihtiyaç duyulmaktadır. Bu güçlüklere rağmen Türkiye’de üretim tesisi sayısı birçok bölgede istikrarlı olarak artmaktadır. Bu da sektörün büyüme potansiyelini devam ettirdiğine dair önemli bir parametredir.

Türkiye çimento sanayinde lokasyon katsayısı tekniğine göre analiz edilen ikinci parametre olan istihdam katsayısı, bölgesel yoğunlaşmayı en iyi yansıtan göstergedir. Buna göre 2014 yılında istihdamda en fazla yoğunluk TR81 Zonguldak alt bölgesi (Zonguldak, Bartın, Karabük), TR52 Konya alt Bölgesi (Konya, Karaman), TRA1 Erzurum alt bölgesi (Bayburt, Erzincan, Erzurum) ve TRA2 Ağrı alt bölgesi (Kars, Ağrı, Iğdır, Ardahan)'dir. İstihdam katsayısına göre en fazla yoğunluk 2019 yılında ise TRC3 Mardin alt bölgesi (Batman, Mardin, Siirt, Şırnak), TR62 Adana alt bölgesi (Mersin, Adana), TR90 Trabzon alt bölgesi (Ordu, Rize, Trabzon, Giresun, Gümüşhane Artvin), TR52 Konya alt bölgesi (Karaman, Konya) ve TR63 Hatay alt 
bölgesindedir (Osmaniye, Kahramanmaraş, Hatay). Genel olarak 2014'ten 2019 yılına gelindiğinde istihdamda yoğunlaşma katsayısında birçok bölge için düşüşler yaşanmıştır. Ancak Özellikle Güneydoğu Anadolu Bölgesi, Doğu Akdeniz ve Orta Anadolu'da yerel girişim yığınlaşmasında olduğu gibi istihdam katsayısı açısından yüksek bir yoğunluk ve kümelenme olduğu gözlenmektedir. Bu bölgelerdeki yoğunlaşma ve kümelenmenin nedeni daha çok sektör yatırım koşullarının bu kesimlerde uygun olması, talep ve pazarın büyüme eğiliminde olması ve ulaşım açısından geniş bir hinterlandın varlığı gibi faktörlerle ilişkilidir.

Sonuç olarak Türkiye çimento sektörü, dünyada önemli bir yere sahip olup kullanılan yüksek teknoloji sayesinde üretim kapasitesini gittikçe artırmaktadır. Sektörün hem tesis sayısı hem de istihdam katsayısına göre bir iki bölge hariç Türkiye'de bütün bölgelerde bir kümelenme ve yığılma gösterdiği anlaşılmaktadır. Özellikle Güneydoğu Anadolu ile Akdeniz Bölgesi sektörün en fazla yığılım gösterdiği bölgeler olup, bu kesimlerde çimento sanayii büyük bir büyüme eğilimi içerisindedir. Söz konusu bölgelerin İran, Rusya, Irak, Suriye gibi pazarlara yakınlığı ve elverişli ulaşım koşulları, bu büyüme trendi üzerinde önemli bir etkiye sahiptir. Diğer yandan dünyada ortaya çıkan ekonomik ve siyasi istikrarsızlar, karbon salınımı ve küresel iklim değişikliği ile ilgili kaygıların giderek artması ve yerel pazarda talebin dalgalanma göstermesi Türk çimento endüstrisinin karşılaştığı en önemli olumsuzluklardır. Bu olumsuzlukları bertaraf etmenin en önemli yolları, çimento üretiminde fosil enerji kaynakları kullanımı ve doğal hammadde kullanımını azaltmak, alternatif ve yenilenebilir enerji kaynaklarına yönelip sürdürülebilir çimento üretimini sağlamak, uluslararası pazarda çeşitliliği artırmak ve ürün çeşitliliği ve teknolojik yatırımları artırmaktan geçmektedir. Bütün bu koşullar sağlandığında Türk çimento sanayisi daha istikrarlı ve sürdürülebilir bir küresel aktör olarak yoluna devam edecektir.

\section{KAYNAKÇA}

Arıöz, Ö., \& Yıldırım, K. (2012). Türkiye'de Çimento Sektöründeki Belirsizlikler Ve Türk Çimento Sektörünün Swot Analizi, DPUJSS, 32(2), 173-190.

Bayraktutan, Y., Tüylüoğlu, İ. \& Özbilgin, M. (2012) “Lojistik Sektöründe Yoğunlaşma Analizi ve Lojistik Gelişmişlik Endeksi: Kocaeli Örneği”, Uluslararası Alanya İşletme Fakültesi Dergisi, 4(3), 61-71.

Çakmak G. (1998). Türk Çimento Sanayiinin Mekânsal Analizi (Yayımlanmamış Yüksek Lisans Tezi). İstanbul: İstanbul Teknik Üniversitesi, Fen Bilimleri Enstitüsü.

Çevik, B. (2016). Çimento Sektörü, İş Bankası İktisadi Araştırmalar Bölümü Raporu.

Çubukçu, K.M. (2015). Planlamada ve Coğrafyada Temel İstatistik ve Mekânsal İstatistik. Ankara: Nobel Yayınları.

Ekincioğlu, O., Gurgun, A.P., Engin Y., Tarhan M. \& Kumbaracıbaşı S., (2013). Approaches for Sustainable Cement Production - A Case Study from Turkey, Energy and Buildings, 66, 136-142.

International Trade Centre, (2021). Trade Map (Kod: 2523). 04.06.2021 tarihinde: https://www.trademap.org/news/trademap_update_trade_indicators_en.html

Isserman, A.M. (1977). The Location Quotient Approach for Estimating Regional Economic Impacts, Journal of the American Institute of Planners, 43(1), 33-41.

Kapkaç, F. (2013). Çimento Çeşitleri, Özellikleri, Hammaddeleri ve Üretim Aşamaları, Maden Tetkik Arama Genel Müdürlüğü, Doğal Kaynaklar ve Ekonomi Bülteni, Ankara.

Kaygalak İ. (2013). Türkiye Sanayi Coğrafyasında Endüstriyel Kümelenme ve Bölgesel Yoğunlaşma Eğilimi. Beşeri Coğrafya Dergisi, 1 (1), 67-81.

Miller M., Gibson J., \& Wright G., (1991). Location Quotient: A Basic Tool for Economic Development Analysis, Economic Development Review, 65-68.

Miller, N., \& Osborne, M. (2014). Spatial differentiation and price discrimination in the cement industry: Evidence from a structural model. The RAND Journal of Economics, 45(2), 221-247.

Moineddin, R., Beyene, J. \& Boyle, E. (2003). On the Location Quotient Confidence Interval, Geographical Analysis, 35(3), 249-256.

Moretti, L. \& Caro, S. (2017). Critical Analysis of the Life Cycle Assessment of the Italian Cement Industry. Journal of Cleaner Production, 152, 198-210.

Özeken, A.A. (1939). Türkiye Çimento Sanayinin İktisadi ve Mali Bünyesi. İstanbul Üniversitesi İktisat Fakültesi Mecmuası, 1, 478-506.

Rekabet Kurumu, (2016). Çimento Sektör Araştırması Raporu. Ankara. 
Sarı, B., Geyik, Ş.Y. \& Keskinkan, O. (2020). Çimento Üretim Sektöründe ISO 14001 Çevre Yönetim Sisteminin Enerji Kazanımı ve İklim Değişikliği Üzerine Etkilerinin İncelenmesi, Çukurova Üniversitesi Mühendislik Mimarlık Fakültesi Dergisi, 35(4), 847-857.

Sungur, O. (2015). TR61 (Antalya, Isparta, Burdur) Bölgesinde Sektörel Yoğunlaşmanın ve Yoğunlaşma Dinamiklerinin Analizi. Yönetim ve Ekonomi Araştırmaları Dergisi, 13(3), 289-315.

Supino S, Malandrino O, Testa M, \& Sica D. (2016). Sustainability in the EU cement industry: The Italian and German experiences. Journal of Clean Production, 112, 430-442.

Syed, R.H., Istiak, A., Ferdous, S.A., \& Monjorul, H., (2020). Empirical Investigation of Energy Management Practices in Cement Industries of Bangladesh. Energy, 212, 1-13.

T.C. Sanayi ve Teknoloji Bakanlı̆̆ı, (2020). Çimento Sektör Raporu 2020, 04.06.2021 tarihinde: https://www.sanayi.gov.tr/plan-program-raporlar-ve-yayinlar/sektorraporlari/mu2001011403

Taner, A.C. (2021). Dünya Çimento Sanayi, Küresel Çimento Üretimi Portföyü, Çimento Marketi, Hazır Beton Zenginliği ve Bolluğu. Global Çimento Fiyatları Eğilimi Perspektifi, TMMBO Fizik Mühendisleri Odası Yayını, 03.06.2021 tarihinde: https://www.fmo.org.tr/faydali-bilgiler/

Tunçez, F.D. (2021). Sürdürülebilir Çimento Üretiminde Çevre Yönetimi Yasal Bileşenleri. Ulusal Çevre Bilimleri Araştırma Dergisi, 4(1), 41-56.

Tüzemen, A. \& Yıldız, Ç. (2018). Geleceğe Yönelik Tahminleme Analizi: Türkiye Çimento Üretimi Uygulaması, Yönetim ve Ekonomi Araştırmaları Dergisi, 16(3), 162-177.

Urhan, F. B. \& Sandal, E. K. (2019). Spatial patterns of Turkish textile industry: Comparative location quotient analysis for 2009 and 2015. International Journal of Geography and Geography Education (IGGE), 40, 172-189.

www.statista.com, (2021). 01.05.20121 tarihinde: https:/www.statista.com/statistics/267364/world-cement-production-bycountry,

Yardımcı, A. (2014). Kapasite Raporlarına Göre Ankara Sanayisinin Kümelenme Eğilimleri. Ekonomik Yaklaşım, 25(92), 5567. 